\section{Effect of topical dexamethasone and ciprofloxacin on bacterial flora of healthy conjunctiva}

SS Ermis ${ }^{1}$, OC Aktepe ${ }^{2}$, UU Inan'1 , F Ozturk and $\mathrm{M}$ Altindis ${ }^{2}$

Keywords: Conjunctival flora; ciprofloxacin; dexamethasone; healthy conjunctiva

Purpose To investigate the effects of topical dexamethasone and ciprofloxacin, alone and in combination, on the colony counts of conjunctival bacterial flora of healthy subjects.

Methods A total of $\mathbf{1 0 0}$ healthy subjects were randomly divided into four groups, consisting of 25 subjects each. Group 1 was treated with dexamethasone phosphate $\mathbf{0 . 1 \%}$ (Maxidex).

Group 2 was treated with ciprofloxacin $0.3 \%$ (Ciloxan) and Group 3 with a combination of these drugs. Group 4 received artificial tear solution (Tears Naturale) and served as control. The drops were administered one drop every $1 \mathrm{~min}$. A pretreatment culture and recultures at 30,90 , and $180 \mathrm{~min}$ after application of final drops were performed on all subjects. The bacterial growth was evaluated in a quantitative manner. All cultures were performed in a double-masked fashion. ANOVA test was used for statistical analyses.

Results While there was no significant difference among mean number of pretreatment colonies between the groups $(P=0.85)$; the differences at 30,90 , and $180 \mathrm{~min}$ were statistically significant $(P<0.001)$. During the study there was no statistically significant change in colony counts in Groups 1 and 4 $(P=0.66$ and 0.55 , respectively). The colony count numbers decreased significantly at 30 and $90 \mathrm{~min}$ in Group $2(P<0.001$ and $P=0.004)$ and at $30 \mathrm{~min}$ in Group $3(P=0.002)$.

Conclusion Topically applied dexamethasone did not cause a significant change in colony counts of the healthy conjunctiva. Both ciprofloxacin and a combination of ciprofloxacin and dexamethasone were effective in the reduction of bacterial ocular flora.

Eye (2004) 18, 249-252. doi:10.1038/

sj.eye. 6700631
Topical corticosteroids are widely used in ophthalmology, alone and in combination with antibiotics. Corticosteroids inhibit the macrophage and neutrophil migration, production of potent chemical mediators, function of immunocompetant cells, and reduce capillary permeability and vasodilatation. It is postulated that this increased spectrum of activity is responsible for increased ocular infection. ${ }^{1,2}$

In this study, we investigated the short-term effects of topical dexamethasone $0.1 \%$ and ciprofloxacin $0.3 \%$, alone and in combination, on the colony counts of conjunctival bacterial flora of healthy subjects. To the best of our knowledge, the effect of topical corticosteroids on ocular bacterial flora has not been investigated. Additionally, it may be important to know whether combined administration of corticosteroid and antibiotic eye drops changes the efficacy of topical antibiotic use.

\section{Materials and methods}

A total of 100 (one hundred) healthy subjects (55 men and 45 women) were randomly divided into four groups, consisting of 25 subjects each. A nurse randomly assigned the subjects into the groups. The right eye of each subject was included in the study. The eyes in Group 1 (dexamethasone group) were treated with three drops of dexamethasone phosphate $0.1 \%$ (Maxidex, Alcon). The eyes in Group 2 (ciprofloxacin group) were treated with three drops of ciprofloxacin $0.3 \%$ (Ciloxan, Alcon) and Group 3 (combination group) with a combination of these drugs, three drops of
Introduction
'Department of Ophthalmology School of Medicine University of Afyon Kocatepe Afyon, Turkey

${ }^{2}$ Department of Microbiology School of Medicine University of Afyon Kocatepe Afyon, Turkey

Correspondence: $\mathrm{S}$ Samet Ermis

Dervispasa mah. Pirireis sk Ceylan apt. A blok No 3/8 03200 Afyon, Turkey Tel: + 902722145299 Fax: +90272 2172029

E-mail: sametermis@ hotmail.com

Received: 21 November 2002

Accepted: 24 April 2003

None of the authors has any proprietary interest in any product mentioned 
ciprofloxacin $0.3 \%$ followed by three drops of dexamethasone phosphate $0.1 \%$. Group 4 (control group) received an artificial tear solution (Tears Naturale, Alcon), which has the same preservative (benzalkonium chloride) as the other two eye drops and served as control. The drops were administered one drop every $1 \mathrm{~min}$. All drops were instilled in to the inferior cul-de-sac.

Before enrolment in the study, patients underwent an ophthalmologic examination. To be eligible, subjects were required to be older than 20 years and to have healthy eyes except from lens opacities. Those who had clinical evidence of inflammatory ocular pathologic features, adnexal or systemic infection, blepharitis, conjunctivitis, previous ocular surgery, evidence of systemic antibiotic or corticosteroid treatment 2 months before the study, or use of topical ocular medications 3 weeks before the study were excluded. Written informed consent was obtained from each subject. All subjects were treated in accordance with the requirements of the Declaration of Helsinki.

A pretreatment culture and recultures at 30,90, and $180 \mathrm{~min}$ after the application of final drops were performed on all subjects. All cultures were performed in a double-masked manner. Neither the person who took the specimens nor the microbiologist who evaluated bacterial growth knew which eye belonged to which group. Specimens were taken by rubbing sterile cottontipped swabs, which were moistened with brain-heart infusion broth, four times to the inferior palbebral conjunctiva in an identical manner in all groups of eyes. No topical anaesthetics were instilled. The lower eyelid was pulled down in order to avoid the lid margins and lashes. Afterwards, all specimens were inoculated onto
$5 \%$ blood agar and chocolate agar immediately. Following $48 \mathrm{~h}$ of incubation at $37^{\circ} \mathrm{C}$, the bacterial growth was evaluated in a quantitative manner as colonyforming units (CFU). The bacterial identification was made according to standard bacteriologic procedures. The mean of CFU counts on the two was recorded. Eyes with pretreatment CFU values less than 25 were excluded from the study.

Comparisons were made using analysis of variance (ANOVA) techniques. Tukey-HSD test was used to determine the significance of differences in CFU values between the groups. A $P$-value of less than 0.05 was considered to be statistically significant.

\section{Results}

There was no significant difference among groups in age $(P=0.90)$ (Table 1$)$.

The mean numbers of pretreatment colonies were 190 CFU in Group 1, 204 CFU in Group 2, 193 CFU in Group 3, and 210 CFU in Group 4. There was no significant difference among groups $(P=0.85)$. The differences of colony counts among the groups at 30,90, and $180 \mathrm{~min}$ were statistically significant $(P<0.001)$ (Tables 2 and 3).

During the study, there was no statistically significant change in colony counts in the dexamethasone and the control group ( $P=0.66$ and 0.55 , respectively). The CFU numbers decreased significantly at 30 and $90 \mathrm{~min}$ in the ciprofloxacin group $(P<0.001$ and $P=0.004)$ and at $30 \mathrm{~min}$ in the combination group $(P=0.002)$ (Figure 1$)$.

In all, 40 eyes were excluded from the study in which pretreatment CFU values were less than 25. The mean age was $56.5 \pm 14.9$ years (range $24-70$ ). The isolation rate

Table 1 Patient characteristics

\begin{tabular}{lccccc}
\hline & Group 1 & Group 2 & Group 3 & Group 4 & P value \\
\hline Age (years) & & & & \\
Mean \pm SD & $54.9 \pm 16.9$ & $57.4 \pm 14.8$ & $55.8 \pm 16.1$ & $57.7 \pm 14.7$ & 0.90 \\
Median & 55 & 57 & 57 & 58 & $23-79$ \\
Range & $22-68$ & $23-74$ & $20-76$ & \\
\hline
\end{tabular}

(Group 1: dexamethasone, Group 2: ciprofloxacin, Group 3: dexamethasone+ciprofloxacin, Group 4: control)

Table 2 Bacterial colony counts and reduction by time and treatment (Mean \pm SD)

\begin{tabular}{llccc}
\hline Subjects & \multicolumn{3}{c}{ Time (min) } \\
\cline { 2 - 5 } & \multicolumn{1}{c}{0} & 30 & 90 & 180 \\
\hline Dexamethasone group & $190 \pm 101$ & $196 \pm 108$ & $181 \pm 124$ & $163 \pm 121$ \\
Ciprofloxacin group & $204 \pm 91$ & $107 \pm 54$ & $73 \pm 46$ & $65 \pm 43$ \\
Combination group & $193 \pm 120$ & $113 \pm 66$ & $104 \pm 71$ & $107 \pm 74$ \\
Control group & $210 \pm 56$ & $224 \pm 86$ & $205 \pm 117$ & $193 \pm 113$ \\
\hline
\end{tabular}


Table 3 Differences of bacterial colony counts between the groups at 30,90 and $180 \mathrm{~min}$

\begin{tabular}{clr}
\hline Minute & Group comparison & \multicolumn{1}{c}{$\mathrm{P}$} \\
\hline 30 & Dexamethasone-ciprofloxacin & 0.001 \\
30 & Dexamethasone-combination & 0.003 \\
30 & Ciprofloxacin-control & $<0.001$ \\
30 & Combination-control & $<0.001$ \\
90 & Dexamethasone-ciprofloxacin & 0.001 \\
90 & Ciprofloxacin-control & $<0.001$ \\
90 & Dexamethasone-combination & 0.027 \\
90 & Combination-control & 0.002 \\
180 & Dexamethasone-ciprofloxacin & 0.002 \\
180 & Ciprofloxacin-combination & 0.021 \\
180 & Ciprofloxacin-control & 0.002 \\
180 & Combination-control & 0.007 \\
\hline
\end{tabular}

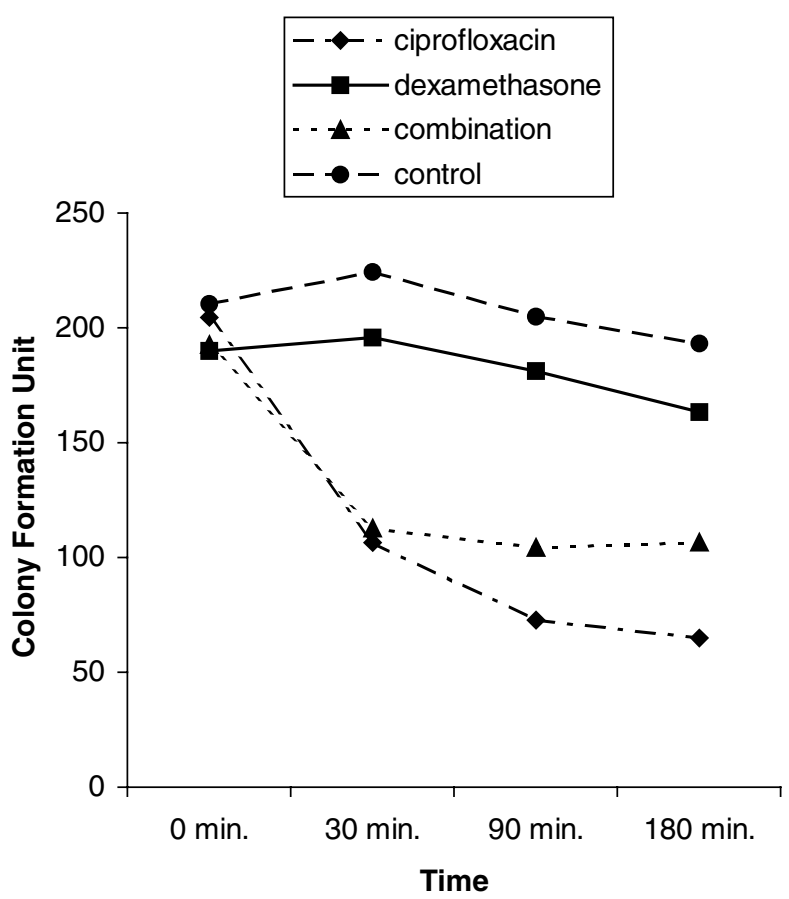

Figure 1 Mean bacterial colony counts and reduction by time and treatment.

of bacteria from the conjunctiva in all eyes was $71.4 \%$. In 19 cases (17\%), two or more species were isolated. The cultures of conjunctiva revealed growth of Staphylococcus aureus $(62 \%)$, coagulase-negative staphylococci $(43 \%)$, Moroxella species (6\%), Haemophilus species (4\%), Group B streptococci (2\%), and Proteus species (2\%).

\section{Discussion}

The eye features protective mechanisms that are nonimmune in nature such as blink reflex and tears. The tear film also provides an immunologic barrier to the environment containing lactoferrin, lysozyme, beta-lysin, immunoglobulins, complement, and cytokines, which have antimicrobial effects. ${ }^{3}$ The conjunctiva contains blood vessels, lymphoid tissue, and immunoreactive cells, including lymphocytes, neutrophils, Langerhans cells, neutrophils, and mast cells. In the normal conjunctival epithelium, small numbers of lymphocytes are interspersed in the epithelial layer, mainly suppressor/cytotoxic T cells. ${ }^{4} \mathrm{~B}$ cells are present in the substantia propria, but in smaller numbers, arranged in aggregates mostly in the fornices. Langerhans cells are the major antigen-presenting cells of the conjunctiva and are located in the epithelium. ${ }^{5}$ Scattered neutrophils are found in the epithelium and substantia propria. Eosinophils and basophils are not present in normal conjunctiva but are present in disease states. ${ }^{3}$

The existence of bacterial flora in clinically healthy conjunctiva has been reported. ${ }^{6,7}$ The number of bacteria in the conjunctiva may be important especially in postsurgical eyes. The external ocular tissues of most subjects harbour organisms capable of causing endophthalmitis if introduced into the anterior chamber during surgery. Speaker $e t a l^{8}$ confirmed a previously held belief that most cases of postoperative endophthalmitis are caused by pathogens of the patient's own flora from the eyelid, conjunctiva, or nose. In our study, topically applied ciprofloxacin significantly reduced colony counts of the healthy conjunctiva during 180 min (Table 2 and Figure 1). Ciprofloxacin can be considered for reducing ocular surface flora before ophthalmic surgery.

Corticosteroids are readily absorbed by the cornea, conjunctiva and sclera after ophthalmic delivery. ${ }^{2}$ Systemic absorption of steroids after topical treatment was reported to be considerable, and if given to a patient with hay fever, it may improve systemic symptoms and decrease the blood eosinophil count. ${ }^{9}$ Steroids may be used in clinical ophthalmic practice for post-traumatic control of inflammation, abnormalities of excessive immunoreactivity, and for diseases that have combined immune and infectious processes. Secondary infections enhanced by corticosteroids can take the form of bacterial conjunctivitis and keratitis. Impaired neutrophil function probably interferes with the control of normal conjunctival flora and predisposes the eye to infections; so it may be important to know the effects of corticosteroid eye drops on ocular bacterial flora. In our study, we found that three drops of topically applied dexamethasone did not cause a significant change in colony counts of the healthy conjunctiva during $180 \mathrm{~min}$ (Table 2 and Figure 1).

Corticosteroids exert their effect by binding to receptors in the cytoplasm. The steroid-receptor complex 
has a high affinity for nuclear interphase chromosomes and thus binds to chromosomal DNA and leads to new protein synthesis. Cells exposed to corticosteroids synthesize and release phospholipase $\mathrm{A}_{2}$-inhibitory glycoprotein. The inhibition of phospholipase $\mathrm{A}_{2}$ leads to a reduction in the release of arachidonic acid, thereby slowing production of arachidonic acid metabolites. Administration of corticosteroids results in a complex series of changes in the actions of cells involved in inflammatory reactions. After a single systemic dose of corticosteroids, there is a net increase in the number of circulating neutrophils, accompanied by a decrease in the margination, migration, and accumulation of neutrophils at sites of inflammation, which reduces the signs of acute inflammation. ${ }^{10}$

Corticosteroids directly suppress the action of cells involved in the inflammatory response, inhibiting phagocytosis by neutrophils and monocytes, the production of degenerative enzymes such as collagenase and plasminogen activator by netrophils, and the production of inflammatory lymophokines and monokines. The inhibition of these factors prevents the vasodilatation and increased vascular permeability components of the inflammatory response. ${ }^{1,10,11}$

Corticosteroids are commonly used in ophthalmology to decrease postsurgical inflammation and there is evidence linking corticosteroids with postoperative ocular infection. ${ }^{2,12,13}$ Treatment of disorders such as disciform herpes, bacterial corneal ulcers and control of postoperative inflammation is performed with the combined use of topical corticosteroids and antibiotics. In a study, a combination of fluoromethalone and gentamicin eye drops was reported to be effective in the reduction of ocular bacterial flora after cataract surgery. ${ }^{14}$ In our study, when dexamethasone and ciprofloxacin were used together, there was a significant reduction in conjunctival flora but less than when ciprofloxacin was used alone. Dexamethasone decreases the reduction of bacterial flora in combination with ciprofloxacin at $180 \mathrm{~min}$, however, the combination reduced colony counts at 30, 90 and $180 \mathrm{~min}$ when compared with the control group (Table 3).

The medications used in this study were all preserved with bezalkonium chloride (the concentration is $0.01 \%$ for dexamethasone and artificial tear solution, $0.006 \%$ for ciprofloxacin). It is possible that bezalkonium chloride may have an effect on conjunctival flora despite a very small amount in three drops.

It is clear that phagocytic killing by leucocytes is an important defence mechanism against bacterial infection, as patients with abnormalities of neutrophil dysfunction are susceptible to recurrent or persistent infections. ${ }^{15}$ As a conclusion, topically applied dexamethasone did not cause a significant change in colony counts of the healthy conjunctiva in the short term. However, it is necessary to investigate whether prolonged use of corticosteroids induces significant changes in the conjunctival flora. Both ciprofloxacin and combination of ciprofloxacin and a dexamethasone were effective in the reduction of ocular bacterial flora.

\section{References}

1 Flach AJ. Treatment of postoperative inflammation in ophthalmology. J Toxicol Cutan Ocular Toxicol 1991; 10: 253-277.

2 Havener WH. Ocular Pharmacology, 5th ed. CV Mosby Co: St Louis, MO, 1983.

3 Seamone CD, Jackson WB. Immunology of the external eye. In: Tasman W, Jaeger EA (eds). Clinical Ophthalmology. Lippincott-Raven: Philadelphia, PA, 1997, pp 1-52.

4 Sacks EH, Wieczorek R, Jakobiec FA, Knowles DM Lymphocytic subpopulations in the normal human conjunctiva: a monoclonal antibody study. Ophthalmology 1986; 93: 1276-1238.

5 Sacks EH, Rutgers J, Jakobiec FA, Bonetti F, Knowles DM. A comparison of conjunctival and nonocular dendritic cells utilising new monoclonal antibodies. Ophthalmology 1986; 93: 1089-1097.

6 Watanabe K, Watanabe KM, Hayasaka S. Methicilinresistant Staphylococci and ofloxacin-resistant bacteria from clinically healthy conjunctivas. Ophthalmic Res 2001; 33: 136-139.

7 Ugomori S, Hayasaka S, Setogawa T. Polyphormonuclear leukocytes and bacterial growth of the normal and mildly inflamed conjunctiva. Ophthalmic Res 1991; 23: 40-44.

8 Speaker MG, Milch FA, Shah MK, Eisner W, Kreiswirth BN. Role of external bacterial flora in the pathogenesis of acute postoperative endophthalmitis. Ophthalmology 1991; 98: 639-649.

9 Abelson MB, Butrus S. Corticosteroids in ophthalmic practice. In: Albert DM, Jakobiec FA (eds). Principles and Practice of Ophthalmology: WB Saunders: Philadelphia, PA, 1994, pp 1013-1022.

10 Goodwin JS. Anti-inflammatory drugs. In: Stites DP, Terr AI, Parslow TG (eds). Medical Immunology. Aplleton \& Lange: Connecticut, 1997, pp 852-855.

11 Flach AJ. Cyclo-oxygenase inhibitors in ophthalmology. Surv Ophthalmol 1989; 36: 259-284.

12 Abelson MB, Schaefer K. Conjunctivitis of allergic origin: immunologic mechanisms and current approaches to therapy. Surv Ophthalmol 1993; 38: 115-132.

13 Friedlander $\mathrm{MH}$. Corticosteroid therapy of ocular inflammation. Int Ophthalmol Clin 1983; 23: 175-182.

14 van Endt JJ, Veraart HG, Kramer R, Janssen AG, Sunder RP. A comparison of two ophthalmic steroid-antibiotic combinations after cataract surgery. Eur J Ophthalmol 1997; 7: 144-148.

15 Palestine AG, Meyern SM, Fauci AS, Gallin JI. Ocular findings in patients with neutrophil dysfunction. Am J Ophthalmol 1983; 95: 598-604. 